\title{
Lewis phenotype, secretor status, and coeliac disease
}

\author{
W Dickey, J D C Wylie, J S A Collins, K G Porter, R G P Watson, J C McLoughlin
}

\begin{abstract}
Patients who cannot secrete $\mathrm{ABO}$ and Lewis blood group antigens into body fluids, an ability controlled by a single gene on chromosome 19, are known to be at increased risk of certain autoimmune diseases associated with human leucocyte antigen (HLA) markers. This study investigated the possibility of an association with coeliac disease using red cell Lewis (Le) blood group phenotype to infer secretor status. Among 73 patients with coeliac disease who had Le $a$ or $b$ antigen, $48 \%$ were nonsecretors (Le a+ b-) compared with $27 \%$ of 137 blood donors ( $p=0.004$ : odds ratio $2 \cdot 49$, $95 \%$ confidence intervals $1 \cdot 37$ to $4 \cdot 51$ ) and $26 \%$ of 62 medical and nursing staff controls ( $p=0.014$ : odds ratio $2 \cdot 65,95 \%$ confidence intervals 1.27 to $5 \cdot 50)$. Clinical characteristics did not differ between secretors and nonsecretors with coeliac disease. Thus, the nonsecretor state is significantly associated with coeliac disease, suggesting that genes on chromosome 19 may directly or indirectly participate in conferring susceptibility.
\end{abstract}

(Gut 1994; 35: 769-770)

The ability to secrete $\mathrm{ABO}$ blood group antigens into saliva and other body fluids is a dominantly inherited characteristic controlled by a single gene on chromosome 19. Patients who cannot secrete these antigens (non-secretors) are at greater risk of various bacterial and fungal infections, ${ }^{1}$ of gastroduodenal disease, ${ }^{2}$ and of some autoimmune conditions, notably ankylosing spondylitis, non-insulin dependent diabetes mellitus, and Graves' disease. ${ }^{3-5}$ The mechanisms underlying these associations are not understood.

Coeliac disease arises after immunological sensitisation of the small bowel to dietary gluten and is associated with certain genes of the major histocompatibility complex on chromosome 6: environmental factors are important in the development of overt disease and non-HLA associated genes probably also confer susceptibility. ${ }^{6}$

As secretor status is closely associated with expression of Lewis antigens both in secretions and on erythrocytes, determination of red cell Lewis phenotype provides a simple method for measuring the prevalence of non-secretors within populations. We used this method to discover if there is a link between secretor status and coeliac disease.

\section{Patients and methods}

We studied patients with coeliac disease attending our gastroenterology clinics over a four month period. At initial presentation, all had had biopsy specimens of jejunum obtained by Crosby capsule or of distal duodenum by forceps, which had shown villous atrophy and increased numbers of intraepithelial lymphocytes and of inflammatory cells in the lamina propria.

Two control populations were studied: blood donors attending a centre in Belfast, and nursing and medical staff of our hospitals who had never been diagnosed as having coeliac disease or dermatitis herpetiformis and had no history of anaemia or of gastrointestinal symptoms.

Red cell Lewis phenotype was determined by standard haemagglutination techniques using commercially available anti-Lewis a and antiLewis b blood grouping reagents (Organon Teknika, Durham, North Carolina).

Results were analysed using $\chi^{2}$ with Yates's correction for $2 \times 2$ tables and the crossed odds ratio with $95 \%$ confidence intervals to estimate the comparative risk of coeliac disease associated with the non-secretor state.

\section{Results}

We tested 75 patients with coeliac disease, 145 blood donors, and 67 staff controls for Lewis phenotype. Of these, two patients (3\%), eight blood donors $(6 \%)$, and five staff controls $(7 \%)$ were both Lewis a and $b$ antigen negative. As secretor status cannot be inferred from this phenotype, they were excluded from further study. The Table shows the prevalence of nonsecretors among the remaining members of each group.

There was a significant excess of non-secretors among patients with coeliac disease compared with both blood donors $\left(\chi^{2}=8 \cdot 36, \mathrm{df}=1, \mathrm{p}=\right.$ $0.004)$ and staff controls $\left(\chi^{2}=6.08, \mathrm{df}=1\right.$, $\mathrm{p}=0.014)$. The odds ratio for coeliac disease with non-secretors was 2.49 ( $95 \%$ confidence intervals 1.37 to 4.51 ) using blood donors as controls and $2.65(1.27$ to 5.50$)$ when compared with staff controls.

A number of clinical characteristics was compared between secretors and non-secretors with coeliac disease. There was no association between patient sex, childhood (age $<16$ years) $v$ adult onset of symptoms, age of onset of symptoms, age at diagnosis, presenting symptoms (presence of diarrhoea/steatorrhoea $v$ absence), or haemoglobin concentration at presentation, and secretor status.

Prevalence of non-secretors among patients with coeliac disease, blood donors, and staff controls

\begin{tabular}{lclc}
\hline Group & Total & $\begin{array}{l}\text { Non-secretors } \\
(\text { Le } a+b-)(\%)\end{array}$ & $\begin{array}{l}\text { Secretors } \\
(\text { Le } a-b+)(\%)\end{array}$ \\
\hline Coeliac disease & 73 & $35(48)$ & $38(52)$ \\
Blood donors & 137 & $37(27)$ & $100(73)$ \\
Staff controls & 62 & $16(26)$ & $46(74)$ \\
\hline
\end{tabular}

Le $=$ Lewis blood group phenotype
Mater Infirmorum J C McLoughlin Correspondence to: Dr W Dickey, Department of Medicine, Institute of Clinica Science, Grosveno
Belfast BT12 6BJ

Accepted for publication 7 July 1993 


\section{Discussion}

Secretors usually possess the red cell Lewis phenotype Le $(a-b+)$. A minority have Le $(a-$ $\mathrm{b}-)$ red cells. Conversely, non-secretors have Le $(a+b-)$ or Le $(a-b-)$ phenotypes as determined by erythrocyte markers. Thus, secretor status cannot be inferred by this method in patients with the $\mathrm{Le}(\mathrm{a}-\mathrm{b}-)$ phenotype but as they are uncommon, determination of red cell Lewis phenotype permits inference of secretor status in most subjects. This method avoids the potential problem of false positive secretors when saliva is tested for $\mathrm{ABO}$ and Lewis group antigens, as a result of contamination by blood from poor oral hygiene, periodontal disease or over vigorous brushing of teeth. ${ }^{7}$ The prevalence of non-secretors among our control groups is comparable with control populations elsewhere in the British Isles.'

The genetic factors participating in the inheritance of coeliac disease are not fully understood. The importance of the HLA genes of the major histocompatibility complex on chromosome 6 is well recognised, but this association merely confers an increased susceptibility and other genes may also be important. The possibility that a second gene located on chromosome 14 in or near the region coding for immunoglobulin heavy chain allotypes ( $\mathrm{Gm}$ types) might be implicated has been explored. Kagnoff et al ${ }^{8}$ reported an association of the phenotype $\mathrm{Gm}$ $(\mathrm{f} ; \mathrm{n} ; \mathrm{b})$ with coeliac disease in patients lacking HLA-B8 and HLA-DR3, but others failed to confirm this. ${ }^{9}$

The hypothesis that secretor status, controlled by a single gene on chromosome 19 , is linked to susceptibility to coeliac disease is an attractive one. An association with the non-secretor state and a number of immunologically mediated diseases associated with HLA markers has been shown by Blackwell and others in Edinburgh. Compared with a prevalence of non-secretors in healthy controls of $27 \%$, that among patients with ankylosing spondylitis was $49 \%,{ }^{3}$ with noninsulin dependent diabetes mellitus $40 \%,{ }^{+}$and with Graves' disease 44\%.'

To our knowledge, only one previous study has compared the prevalence of non-secretors among patients with coeliac disease with that of controls. Using saliva samples to determine secretor status, Langman et $a l^{10}$ reported that only $14 \%$ of 50 patients with coeliac disease in Birmingham were non-secretors, compared with $27 \%$ of 92 coeliac patients in London and $22 \%$ of 591 healthy controls: there was no statistical difference between the groups. There may be considerable discrepancy between the nonsecretor prevalence assessed by saliva testing and by determination of Lewis phenotype, because of contamination of saliva by blood: Blackwell et al obtained figures of 25 and $38 \%$ respectively in one area. ${ }^{7}$ In addition, patients with coeliac disease are more likely to have mouth ulcers and other oral lesions, and we postulate that a higher risk of blood contamination of saliva as a result among coeliac patients may have led to an underestimation of non-secretor prevalence in this group when tested by Langman et al. This would at least partly explain the discrepancy with our study's outcome.

Our results suggest that the occurrence of coeliac disease is indeed significantly associated with the non-secretor state. Predisposition to coeliac disease may be related to some aspect of immune function that is changed in nonsecretors, although the exact mechanism is unclear.' Reports of reduced concentrations of salivary and serum IgA in non-secretors, suggesting an abnormality in mucosal protection," have not been substantiated by other workers. ${ }^{12}$ The increased susceptibility of non-secretors to various infections had led Blackwell to propose that association with the non-secretor state in certain autoimmune conditions is evidence for an infective aetiology.' While prior adenovirus 12 infection has been considered in the pathogenesis of coeliac disease, ${ }^{13}$ this has not been substantiated $^{14}$ and some virus infections seem to be associated with the secretor rather than the nonsecretor state. ${ }^{15}$ Alternatively, linked genes on chromosome 19 may determine independently secretor status and the risk of developing coeliac disease.

Assessment of HLA phenotype in combination with secretor status may identify those first degree relatives of patients with coeliac disease at greatest risk of developing the condition, but family studies will be required to confirm this. Secretor status, however, like the HLA phenotypes associated with coeliac disease, is common in the general population and therefore confers susceptibility and not disease. Other genes may well be implicated in the pathogenesis.

Data from this study were presented at the British Society of Gastroenterology, Warwick, 15-17 September 1993 and published as an abstract (Gut 1993; 34 (suppl) S23.

1 Blackwell CC. Genetic susceptibility to infectious agents. Proc $R$ Coll Phys Edinb 1989; 19: 129-38

2 Dickey W, Collins JSA, Watson RGP, Sloan JM, Porter KG Secretor status and Helicobacter pylori infection are independent risk factors for gastroduodenal disease. Gut 1993; 34: 351-3.

3 Shinebaum R, Blackwell CC, Forster PJG, Hurst NP, Weir DM, Nuki G. Non-secretion of ABO blood group antigen as a host susceptibility factor in the spondyloarthropathies. $B M \mathcal{F} 1987 ; 294: 208-10$.

4 Blackwell CC, James VS, Weir DM, Gemmill JD, Patrick AW, Collier A, et al. Secretor state of patients with insulin dependent or non-insulin dependent diabetes mellitus. $B M \mathcal{F}$ 1987; 295: 1024-5.

5 Collier A, Patrick AW, Toft AD, Blackwell CC, James V, Weir DM. Increased prevalence of non-secretors in patients with Graves' disease: evidence for an infectious aetiology? $B M F$ 1988; 296: 1162.

6 Kelleher D. The genetics of coeliac disease. Eur $\mathcal{F}$ Gastroentero Hepatol 1991; 3: 115-8.

7 Blackwell CC, Weir DM, James VS, Cartwright KAV, Stuart JM, Jones DM. The Stonehouse study: secretor status and carriage of Neisseria species. Epidemiol Infect 1989; 102 $1-10$.

8 Kagnoff MF, Weiss JB, Brown RJ, Lee T, Schanfield MS Immunoglobulin allotype markers in gluten-sensitive enteropathy. Lancet 1983; i: 952-3.

9 Hannigan M, Bourke M, Stevens FM, McCarthy CF. Gm typing of Irish coeliac patients and controls does not help locate the 'second' coeliac gene. Ir 7 Med Sci 1991; 160: $57-8$

10 Langman MJS, Banwell JG, Stewart JS, Robson EB. ABO blood groups, secretor status, and intestinal alkaline phosphatase concentrations in patients with celiac disease. Gastroenterology 1969; 57: 19-23.

11 Waissbluth JG, Langman MJS. ABO blood groups, secreto status, salivary protein, and serum and salivary immunoglobulin concentrations. Gut 1971; 12: 646-9.

12 Blackwell CC, Jonsdottir K, Weir DM, Hanson MF Cartwright KAV, Stewart J, et al. Blood groups, secretor status and susceptibility to bacterial meningitis. FEMS Microbiol Immunol 1989; 47: 351-6.

13 Arato A, Kosnai I, Szonyi L, Toth M. Frequent past exposure to adenovirus 12 in coeliac disease. Acta Paediatr Scand 1991; 80: 1101-2.

14 Mahon J, Blair GE, Wood GM, Scott BB, Losowsky MS Howdle PD. Is persistent adenovirus 12 infection involved Howdle PD. Is persistent adenovirus 12 infection involved
in coeliac disease? A search for viral DNA using the

15 Raza MW, Blackwell CC, Molyneaux P, James VS, Ogilvie MM, Inglis JM, et al. Association between secretor status and respiratory viral illness. BMF 1991; 303: 815-8. 